\title{
Sequence and Regulatory Variation in Acetylcholinesterase Genes Contribute to Insecticide Resistance in Different populations of Leptinotarsa decemlineata
}

\author{
Aigi Margus ${ }^{1}$, Saija Piiroinen ${ }^{1}$, Philipp Lehmann², Alessandro Grapputo ${ }^{3}$, Leona Gilbert ${ }^{4}$, \\ Yolanda Chen ${ }^{5}$, and Leena Lindström ${ }^{1}$ \\ ${ }^{1}$ Jyvaskylan yliopisto Matemaattis-luonnontieteellinen tiedekunta \\ ${ }^{2}$ Stockholms Universitet Naturvetenskapliga fakulteten \\ ${ }^{3}$ University of Padova Department of Biology \\ ${ }^{4}$ Te?ted $\mathrm{Oy}$ \\ ${ }^{5}$ University of Vermont
}

September 26, 2021

\begin{abstract}
Although insect herbivores are known to evolve resistance to insecticides through multiple genetic mechanisms, resistance in individual species has been assumed to follow the same mechanism. While both mutations in the target site insensitivity and increased amplification are known to contribute to insecticide resistance, little is known about the degree to which geographic populations of the same species differ at the target site in a response to insecticides. We tested structural (e.g. mutation profiles) and regulatory (e.g. the gene expression of Ldace1 and Ldace2, AChE activity) differences between two populations (Vermont, USA and Belchow, Poland) of the Colorado potato beetle, Leptinotarsa decemlineata in their resistance to two commonly used groups of insecticides, organophosphates, and carbamates. We established that Vermont beetles were more resistant to azinphosmethyl and carbaryl insecticides compared to Belchow beetles, despite a similar frequency of resistance-associated alleles (i.e. S291G) in the Ldace2 gene. However, the Vermont population had two additional amino acid replacements (G192S, F402Y) in the Ldace1 gene, which were absent in the Belchow population. Moreover, the Vermont population showed higher expression of Ldace1 and was less sensitive to AChE inhibition by azinphos methyl oxon than the Belchow population. Therefore, the two populations have evolved different genetic mechanisms to adapt to organophosphate and carbamate insecticides.
\end{abstract}

\section{Hosted file}

Margus_revised2021_EE_clean.docx available at https://authorea.com/users/437945/articles/ 539258-sequence-and-regulatory-variation-in-acetylcholinesterase-genes-contribute-toinsecticide-resistance-in-different-populations-of-leptinotarsa-decemlineata

a) Organophosphate (AZ)

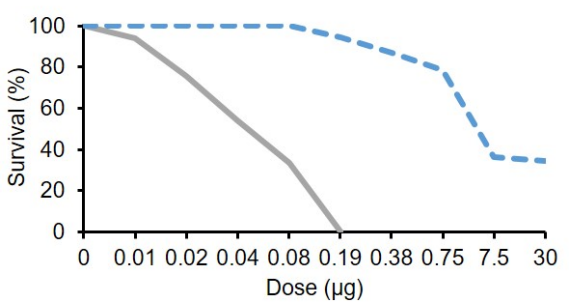

b) Carbamate (CAR)

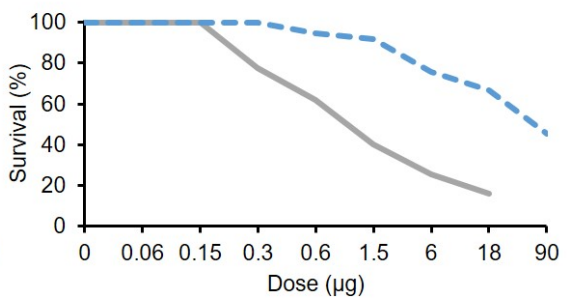




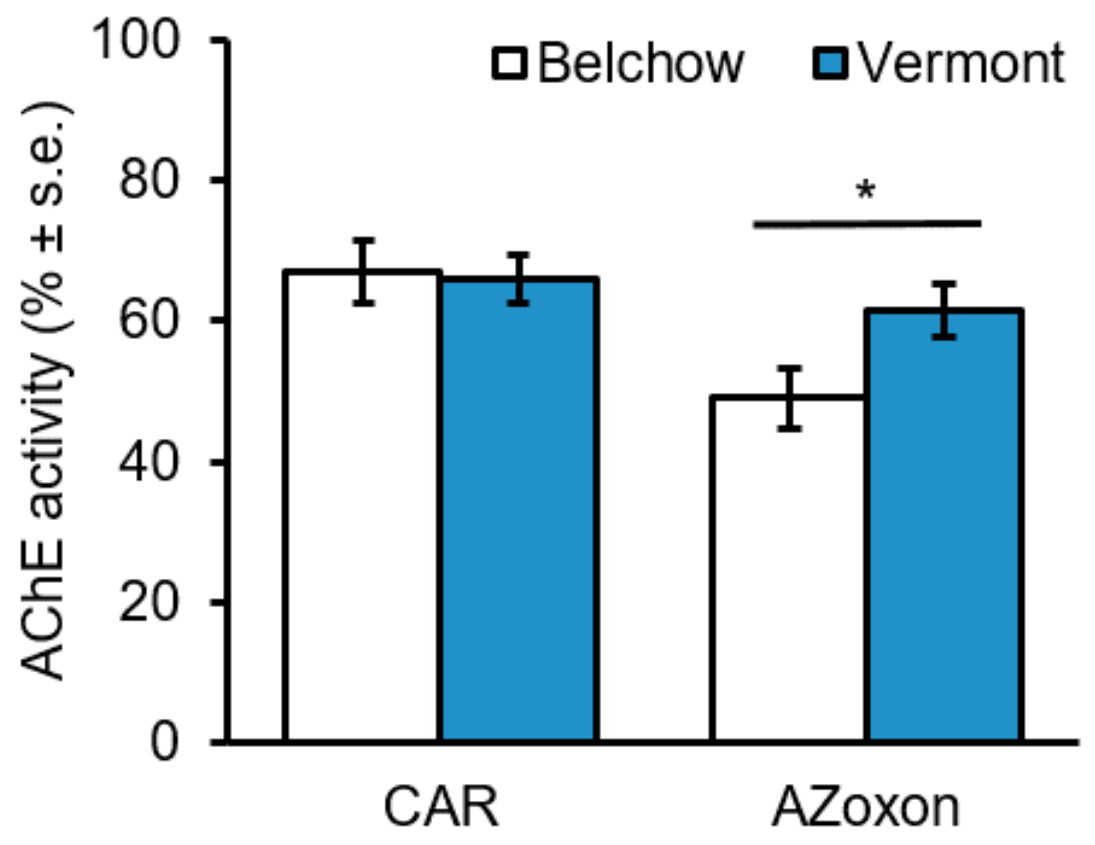


a) Ldace1

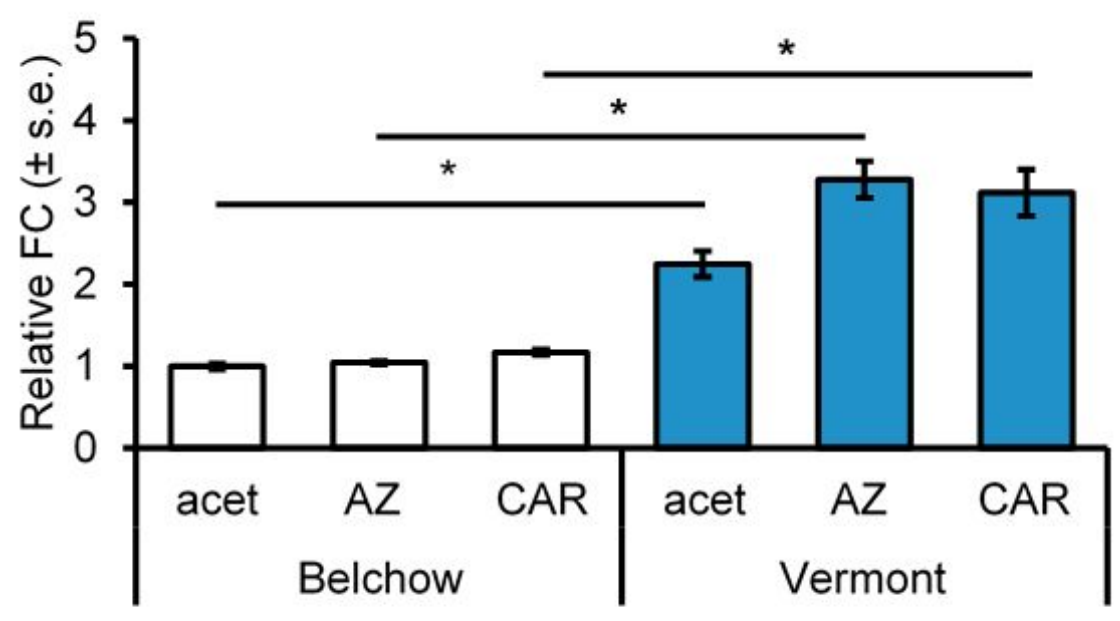

b) Ldace2

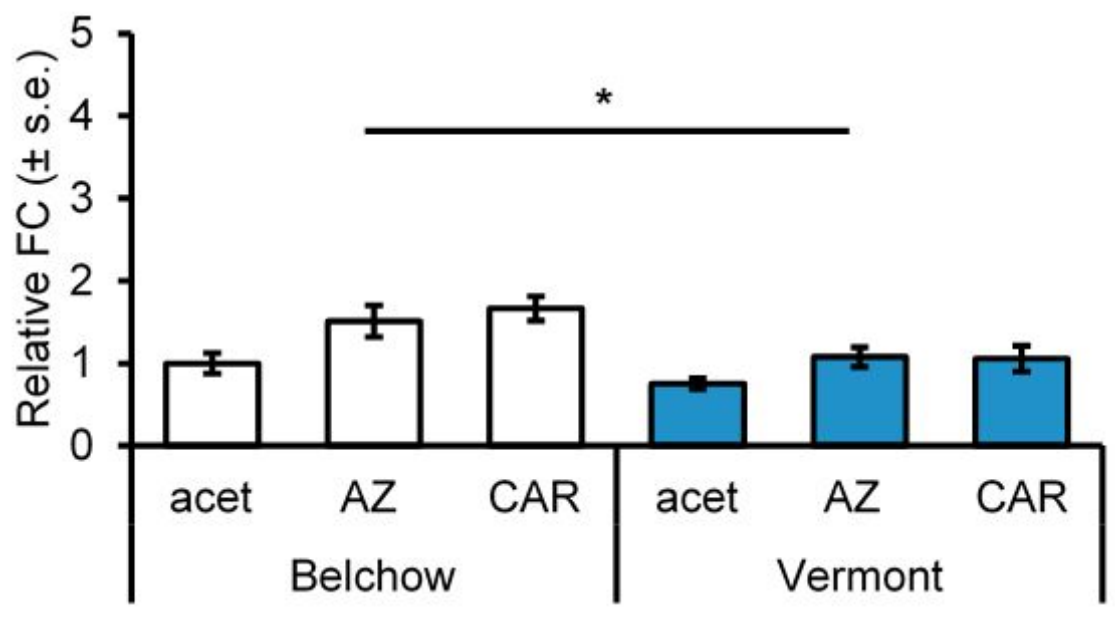



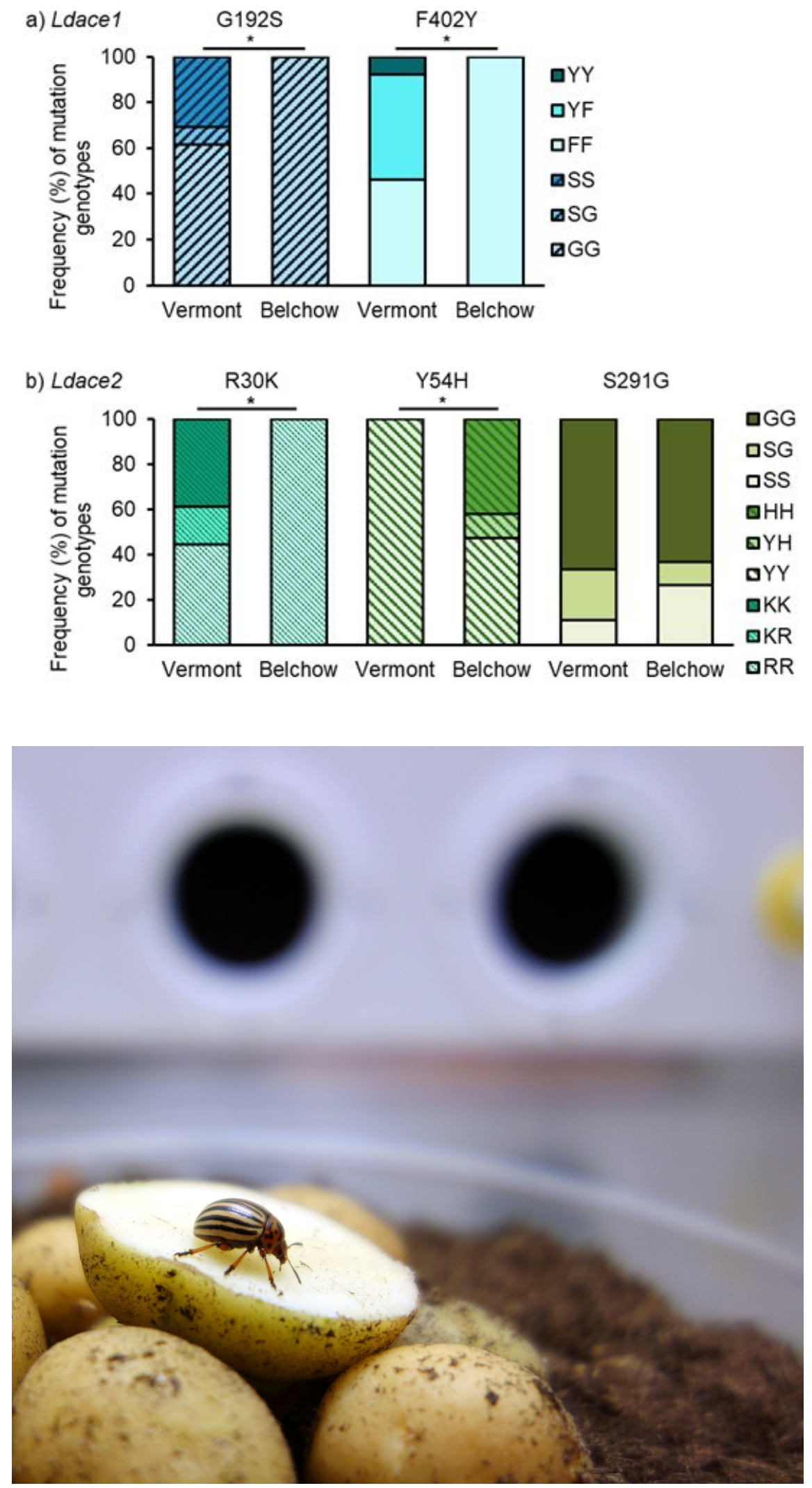